Supporting information

\title{
1,4-Selective Hydrovinylation of Diene Catalyzed by Iron Diimine Catalyst: A Computational Case Study of Two State Reactivity
}

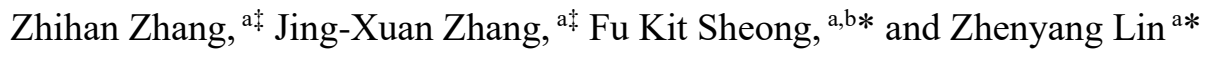 \\ ${ }^{a}$ Department of Chemistry, The Hong Kong University of Science and Technology, Clear Water Bay, \\ Hong Kong, China. \\ ${ }^{b}$ Institute for Advanced Study, The Hong Kong University of Science and Technology, Clear Water \\ Bay, Hong Kong, China.
}

\section{Table of Content}

Figure S1. Spin polarization of ${ }^{3}$ IM0 and ${ }^{1}$ IMO.

Figure S2. Spin natural orbital (SNO) and principal interacting spin orbital (PISO) on ${ }^{\mathbf{5}} \mathbf{I M 0} . \quad$ S3

Figure S3. Dominant PISO pairs of ${ }^{3}{ }^{\text {TS }}$ Oc $_{\text {oc }}$ between the (DI)Fe fragment and substrate. S4

Figure S4. Dominant PISO pairs of ${ }^{1}$ TS Oc $_{\mathbf{O}}$ between the (DI)Fe fragment and substrate. S5

Figure S5. Energy profiles of the full pathway with all three spin states. $\quad$ S6

Figure S6. Dominant PISO pairs of ${ }^{3} \mathbf{T S}_{\text {BHT }}$ between the (DI)Fe fragment and substrate. S7

Figure S7. Dominant PISO pairs of ${ }^{\mathbf{1}} \mathbf{T S}_{\mathbf{B H T}}$ between the (DI)Fe fragment and substrate. S8

Figure S8. Oxidative coupling transition states leading to linear product. S9

Table S1. Overlap matrix between the metal fragment $\alpha$ - and $\beta$-PISOs shown in Figure 3. $\quad$ S9

Table S2. Overlap matrix between the metal fragment $\alpha$-PISOs and SNOs shown in Figure 3. S10

Table S3. Overlap matrix between the metal fragment $\beta$-PISOs and SNOs shown in Figure 3. $\quad$ S10

Table S4. Overlap matrix between the metal fragment $\alpha$ - and $\beta$-PISOs shown in Figure $4 . \quad$ S11

Table S5. Overlap matrix between the metal fragment $\alpha$-PISOs and SNOs shown in Figure 4. $\quad$ S11

Table S6. Overlap matrix between the metal fragment $\beta$-PISOs and SNOs shown in Figure 4. S12

$\begin{array}{ll}\text { Table S7. Total PBI of resting state and key transition states. } & \text { S12 }\end{array}$

Table S8. Calculated relative energies (in $\mathrm{kcal} / \mathrm{mol}$ ) based on full model (TPSSh) and truncated $\begin{array}{ll}\text { model (TPSSh and CASPT2). } & \text { S13 }\end{array}$

$\begin{array}{ll}\text { Scheme S1. Truncation scheme for CASPT2 calculations. } & \text { S13 }\end{array}$ 

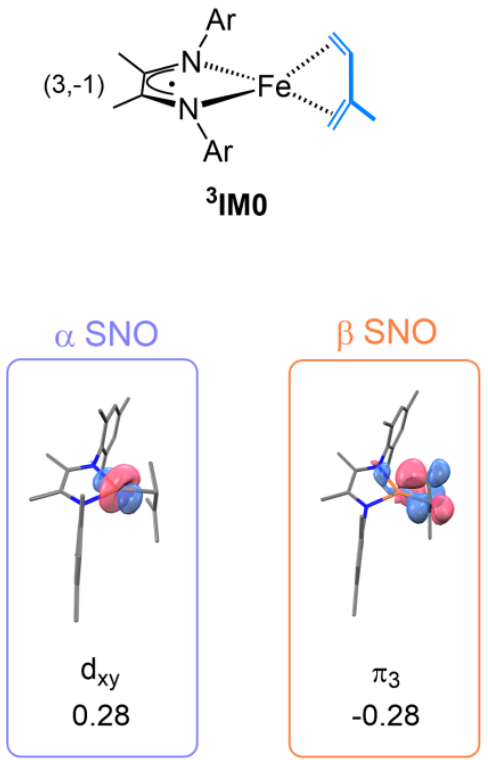

b)

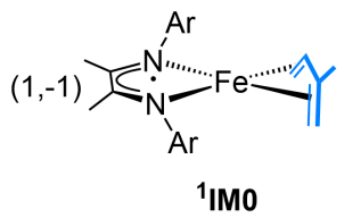
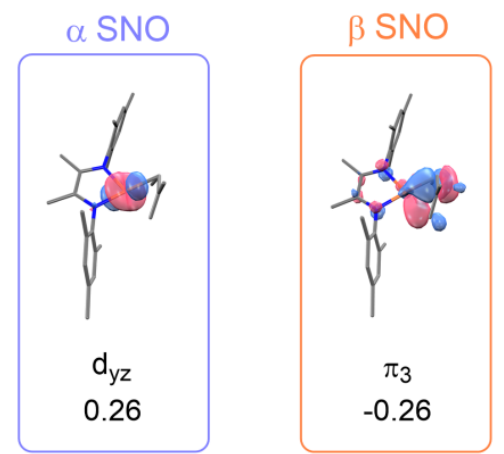

Figure S1. Spin polarization of ${ }^{\mathbf{3}} \mathbf{I M 0}$ and ${ }^{\mathbf{1}} \mathbf{I M 0}$. 


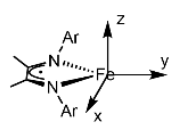

a)
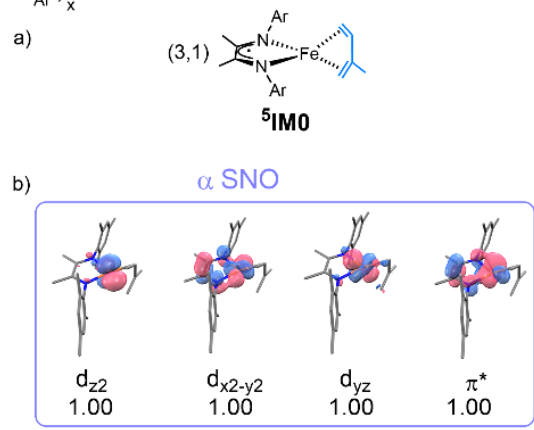

c)

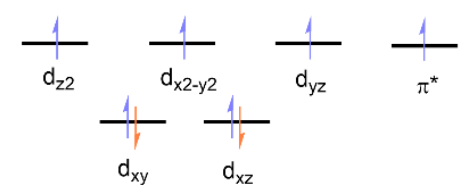

d)
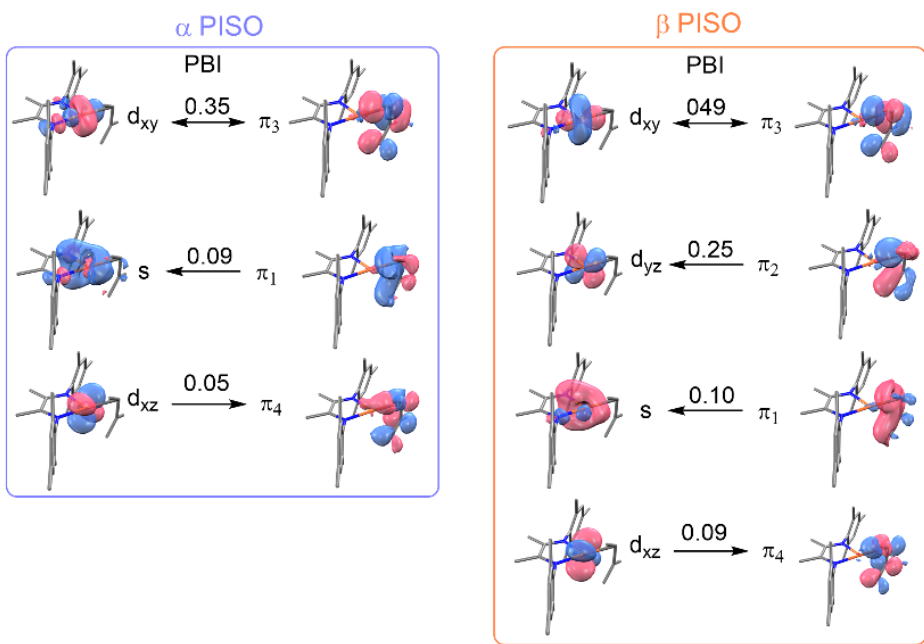

e)

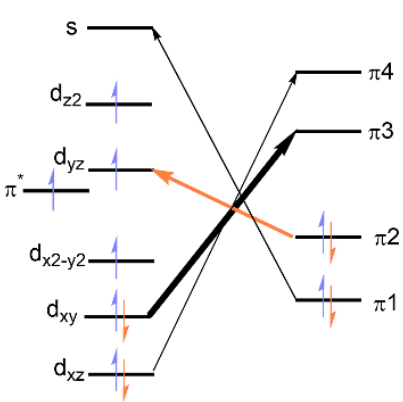

Figure S2. Spin natural orbital (SNO) and principal interacting spin orbital (PISO) analyses on ${ }^{5}$ IM0 as well as an illustrative orbital interaction diagram describing the interaction between the iron diimine catalyst and diene substrate. (a) Lewis structure of ${ }^{\mathbf{5}} \mathbf{I M 0}$ along with the Cartesian coordinate system adopted hereafter. (b) Dominant SNOs of the ${ }^{\mathbf{5}} \mathbf{I M 0}$ state. There is 3 SNOs with eigenvalue close to 1 and localized on the Fe center, as well as one SNO with eigenvalue close to 1 localized on the diimine ligand, consistent with our $(3,1)$ assignment. (c) d electron configuration of the system. (d) Dominant PISO pairs between the (DI)Fe fragment and $\mathrm{C}_{5} \mathrm{H}_{8}$, the 7 PISO pairs presented accounts for $92.4 \%$ of the interaction between the two moieties. (e) Orbital interactions between the frontier orbitals of the (DI)Fe fragment and $\mathrm{C}_{5} \mathrm{H}_{8}$. 


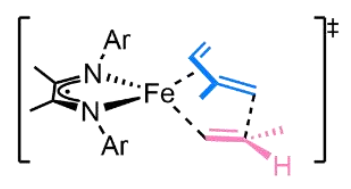

${ }^{3} \mathrm{TS}_{\mathrm{OC}} \quad(3,-1)$
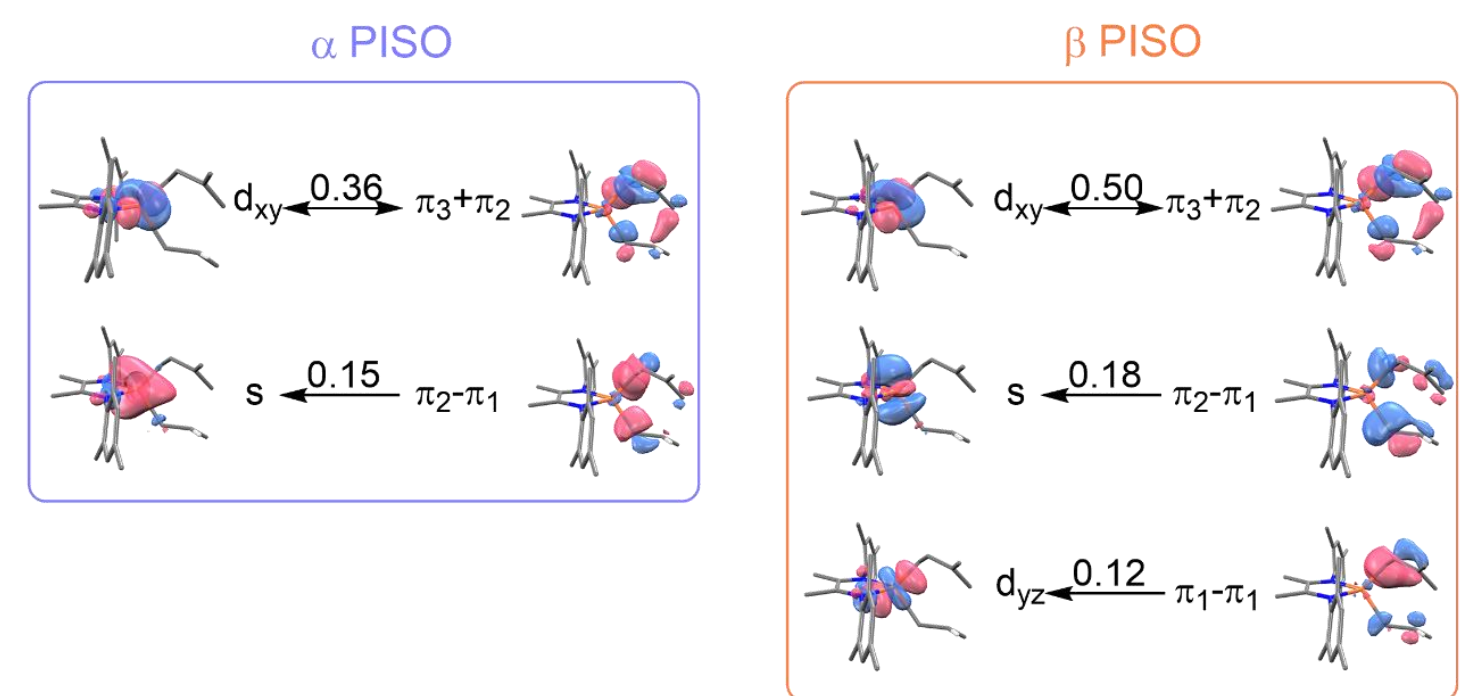

Figure S3. Dominant PISO pairs of ${ }^{3}$ TSoc between the (DI)Fe fragment and substrate, the 5 PISO pairs presented accounts for $79.7 \%$ of the interaction between the two moieties. 


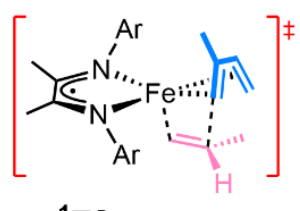

${ }^{1} \mathrm{TS}_{\mathrm{OC}}(1,-1)$
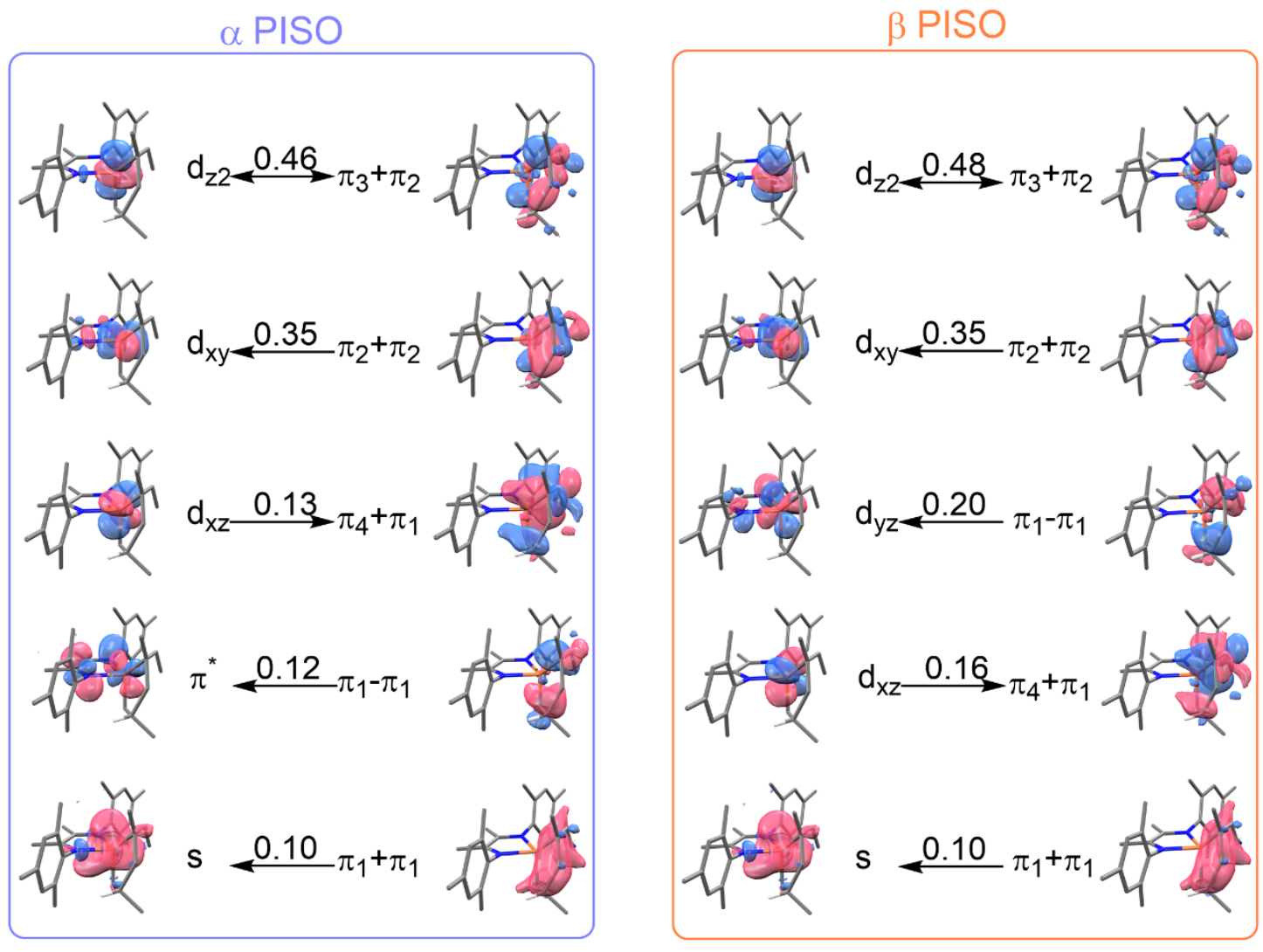

Figure S4. Dominant PISO pairs of ${ }^{\mathbf{1}}$ TSoc between the (DI)Fe fragment and substrate, the 10 PISO pairs presented accounts for $91.2 \%$ of the interaction between the two moieties. 


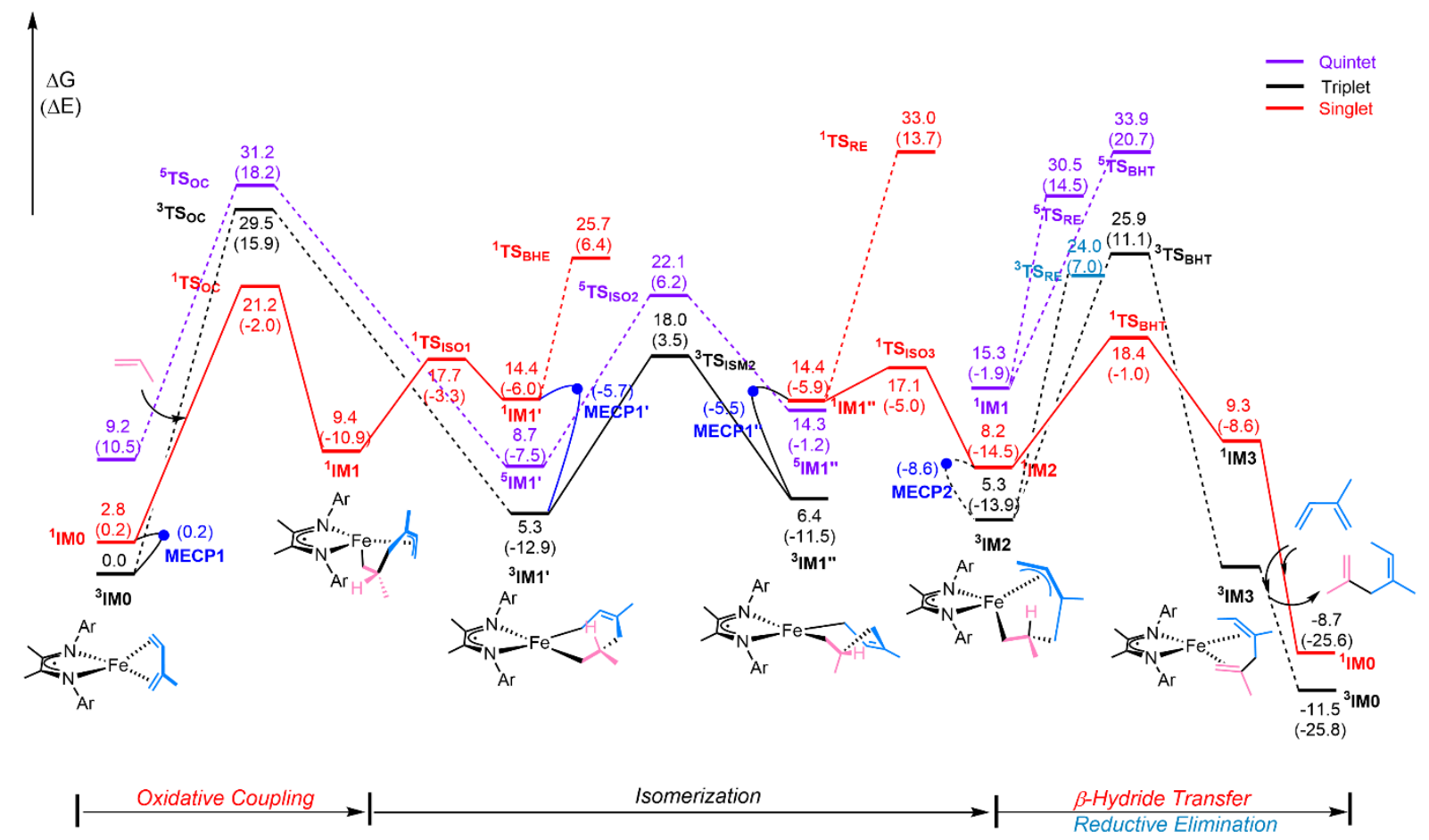

Figure S5. Energy profiles of the full pathway with all three spin states. The relative free energies and electronic energies (in parentheses) are given in $\mathrm{kcal} / \mathrm{mol}$. 


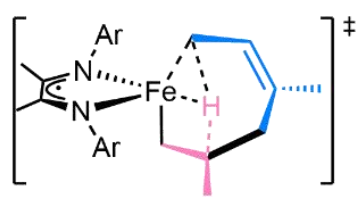

${ }^{3} \mathrm{TS}_{\mathrm{BHT}} \quad(3,-1)$

$\alpha$ PISO

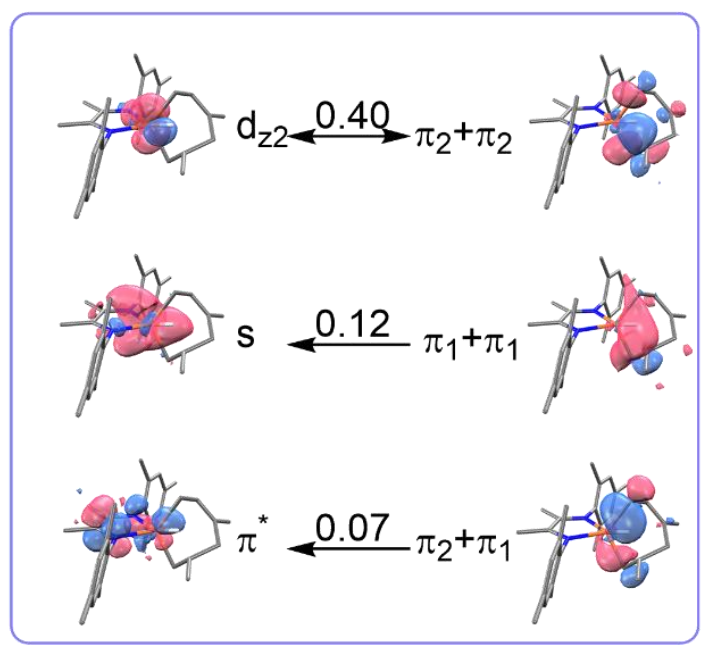

$\beta$ PISO

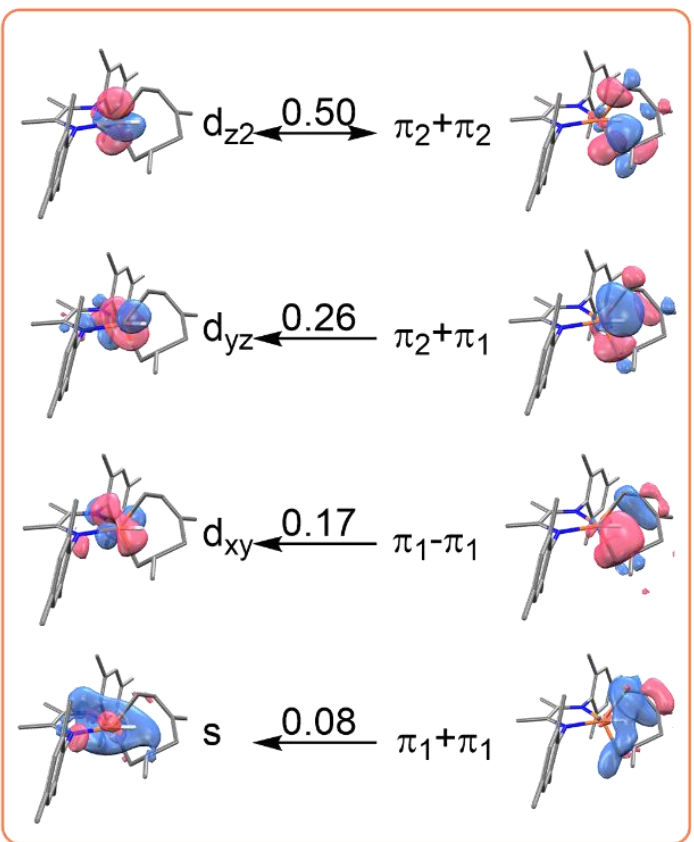

Figure S6. Dominant PISO pairs of ${ }^{3}$ TS PISO pairs presented accounts for $85.3 \%$ of the interaction between the two moieties. 

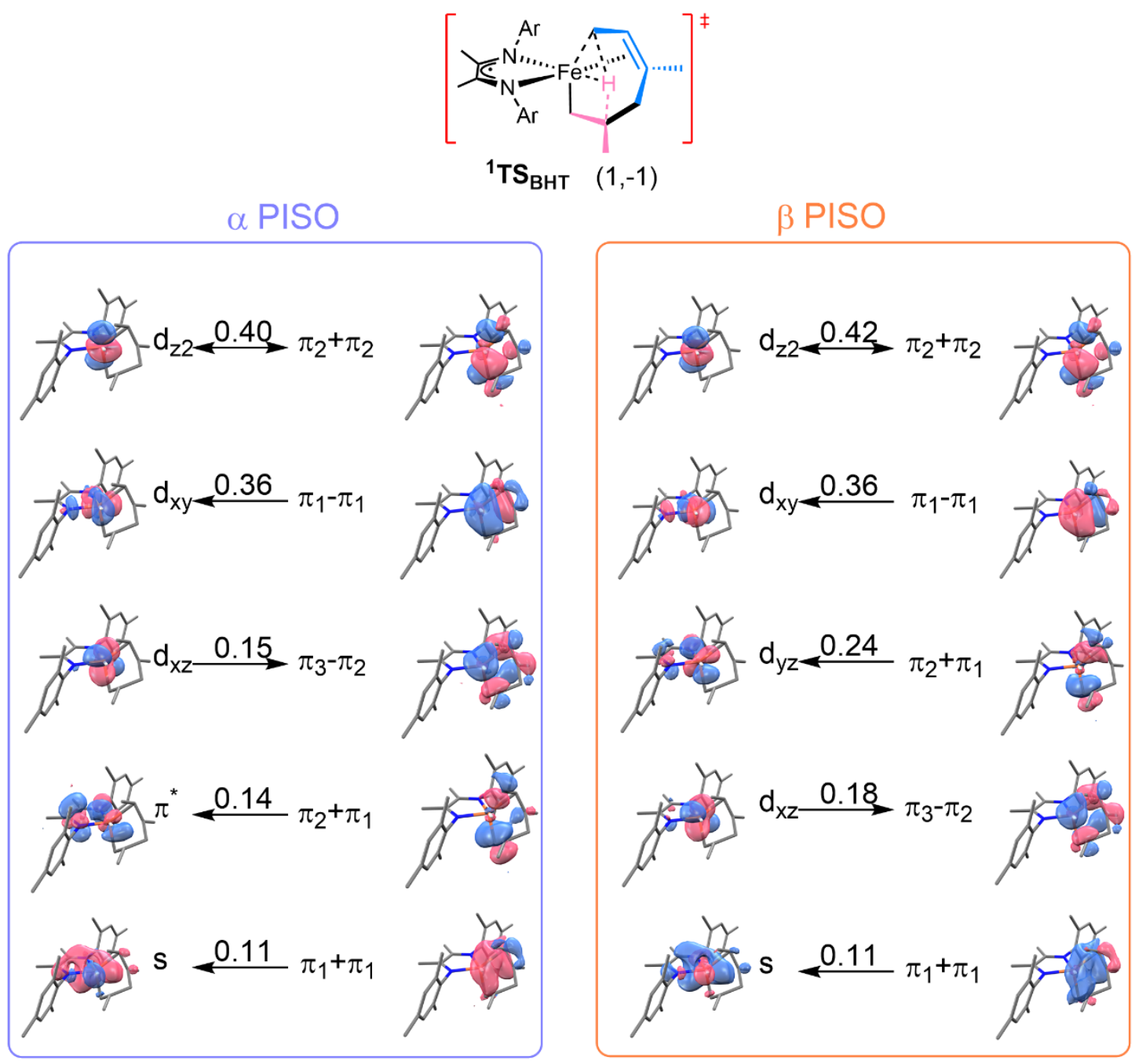

Figure S7. Dominant PISO pairs of ${ }^{\mathbf{1}}$ TS 10 PISO pairs presented accounts for $91.3 \%$ of the interaction between the two moieties. 


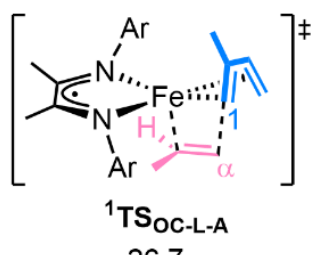

26.7

(2.7)

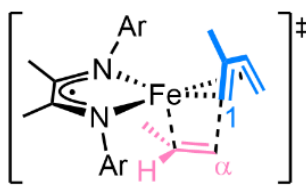

${ }^{1} \mathrm{TS}_{\mathrm{OC}-\mathrm{L}-\mathrm{B}}$

25.7

(2.3)

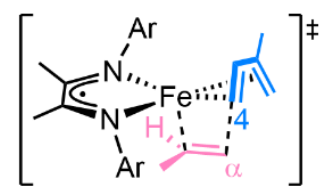

${ }^{1} \mathrm{TS}_{\mathrm{OC}-\mathrm{L}-\mathrm{C}}$

23.1

$(0.1)$

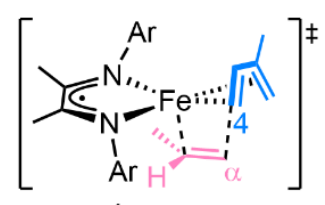

${ }^{1}$ TS OC-L-D

24.0

$(1.3)$

Figure S8. Oxidative coupling transition states leading to linear product with $\mathrm{C}-\mathrm{C}$ formations occurring in $\mathrm{C}^{\alpha}$ of propene. The relative free energies and electronic energies (in parentheses) are given in $\mathrm{kcal} / \mathrm{mol}$.

Table S1. Overlap matrix between the metal fragment $\alpha$ - and $\beta$-PISOs shown in Figure 3.

\begin{tabular}{|c|c|c|c|c|}
\hline $\begin{array}{l}\text { Orbital } \\
\text { overlap }\end{array}$ & $\begin{array}{c}1^{\text {st }} \beta \text {-PISO } \\
\text { (metal side) } \\
d_{x y}\end{array}$ & $\begin{array}{c}2^{\text {nd }} \beta \text {-PISO } \\
\text { (metal side) } \\
d_{y z}\end{array}$ & $\begin{array}{c}3^{\text {rd }} \beta \text {-PISO } \\
\text { (metal side) } \\
\mathrm{s}\end{array}$ & $\begin{array}{c}4^{\text {th }} \beta \text {-PISO } \\
\text { (metal side) } \\
d_{x z}\end{array}$ \\
\hline $\begin{array}{c}1^{\text {st }} \alpha \text {-PISO } \\
\text { (metal side) } \\
d_{x y}\end{array}$ & 0.89 & 0.05 & 0.00 & 0.01 \\
\hline $\begin{array}{c}2^{\text {nd }} \alpha \text {-PISO } \\
\text { (metal side) } \\
\pi^{*}\end{array}$ & 0.01 & 0.61 & 0.02 & 0.12 \\
\hline $\begin{array}{c}3^{\text {rd }} \alpha \text {-PISO } \\
\text { (metal side) } \\
\mathrm{s}\end{array}$ & 0.07 & 0.01 & 0.85 & 0.00 \\
\hline $\begin{array}{c}4^{\text {th }} \alpha \text {-PISO } \\
\text { (metal side) } \\
d_{x z}\end{array}$ & 0.03 & 0.16 & 0.03 & 0.98 \\
\hline
\end{tabular}

*To avoid issues caused by the phase, we took absolute value for all the overlap in Table S1 to S6.

Note for Table S1: Although there are some apparent visual differences between the $1^{\text {st }} \alpha$-PISO and the $1^{\text {st }} \beta$-PISO (especially on the metal side), their overlap is actually quite large, indicating that they are fundamentally the same orbital, only with minor differences in mixing. On the other hand, the $2^{\text {nd }}$ $\alpha$-PISO and the $2^{\text {nd }} \beta$-PISO do not have such a large overlap, and so we assigned them differently. 
Table S2. Overlap matrix between the metal fragment $\alpha$-PISOs and SNOs shown in Figure 3.

\begin{tabular}{|c|c|c|c|c|}
\hline $\begin{array}{l}\text { Orbital } \\
\text { overlap }\end{array}$ & $\begin{array}{c}1^{\text {st }} \alpha \text {-PISO } \\
\text { (metal side) } \\
d_{x y}\end{array}$ & $\begin{array}{c}2^{\text {nd }} \alpha \text {-PISO } \\
\text { (metal side) } \\
\pi^{*}\end{array}$ & $\begin{array}{c}3^{\text {rd }} \alpha \text {-PISO } \\
\text { (metal side) } \\
\mathrm{s}\end{array}$ & $\begin{array}{c}4^{\text {th }} \alpha \text {-PISO } \\
\text { (metal side) } \\
d_{x z}\end{array}$ \\
\hline $\begin{array}{c}1^{\text {st }} \alpha-\text { SNO } \\
d_{22}\end{array}$ & 0.08 & 0.00 & 0.35 & 0.00 \\
\hline $\begin{array}{c}2^{\text {nd }} \alpha-\text { SNO } \\
d_{x 2-y 2}\end{array}$ & 0.14 & 0.06 & 0.36 & 0.00 \\
\hline $\begin{array}{c}3^{\text {rd }} \alpha-\text { SNO } \\
d_{y z}\end{array}$ & 0.01 & 0.32 & 0.01 & 0.15 \\
\hline $\begin{array}{c}1^{\text {st }} \beta-\mathrm{SNO} \\
\pi^{*}\end{array}$ & 0.01 & 0.84 & 0.03 & 0.05 \\
\hline
\end{tabular}

Table S3. Overlap matrix between the metal fragment $\beta$-PISOs and SNOs shown in Figure 3.

\begin{tabular}{|c|c|c|c|c|}
\hline $\begin{array}{l}\text { Orbital } \\
\text { overlap }\end{array}$ & $\begin{array}{c}1^{\text {st }} \beta \text {-PISO } \\
\text { (metal side) } \\
d_{x y}\end{array}$ & $\begin{array}{c}2^{\text {nd }} \beta \text {-PISO } \\
\text { (metal side) } \\
d_{y z}\end{array}$ & $\begin{array}{c}3^{\text {rd }} \beta \text {-PISO } \\
\text { (metal side) } \\
\mathrm{s}\end{array}$ & $\begin{array}{c}4^{\text {th }} \beta \text {-PISO } \\
\text { (metal side) } \\
d_{x z}\end{array}$ \\
\hline $\begin{array}{c}1^{\mathrm{st}} \alpha \text {-SNO } \\
\mathrm{d}_{22}\end{array}$ & 0.14 & 0.00 & 0.01 & 0.00 \\
\hline $\begin{array}{c}2^{\text {nd }} \alpha-S N O \\
d_{x 2-y 2}\end{array}$ & 0.22 & 0.01 & 0.02 & 0.07 \\
\hline $\begin{array}{c}3^{\text {rd }} \alpha-S N O \\
d_{y z}\end{array}$ & 0.00 & 0.89 & 0.00 & 0.06 \\
\hline $\begin{array}{c}1^{\text {st }} \beta-\mathrm{SNO} \\
\pi^{*}\end{array}$ & 0.01 & 0.24 & 0.00 & 0.19 \\
\hline
\end{tabular}


Table S4. Overlap matrix between the metal fragment $\alpha$ - and $\beta$-PISOs shown in Figure 4.

\begin{tabular}{|c|c|c|c|c|}
\hline $\begin{array}{l}\text { Orbital } \\
\text { overlap }\end{array}$ & $\begin{array}{c}1^{\text {st }} \beta \text {-PISO } \\
\text { (metal side) } \\
d_{y z}\end{array}$ & $\begin{array}{c}2^{\text {nd }} \beta \text {-PISO } \\
\text { (metal side) } \\
d_{x y}\end{array}$ & $\begin{array}{c}3^{\mathrm{rd}} \beta \text {-PISO } \\
\text { (metal side) } \\
\mathrm{d}_{\mathrm{xz}}\end{array}$ & $\begin{array}{c}4^{\text {th }} \beta \text {-PISO } \\
\text { (metal side) } \\
\mathrm{s}\end{array}$ \\
\hline $\begin{array}{c}1^{\text {st }} \alpha \text {-PISO } \\
\text { (metal side) } \\
d_{x y}\end{array}$ & 0.14 & 0.98 & 0.06 & 0.03 \\
\hline $\begin{array}{c}2^{\text {nd }} \alpha \text {-PISO } \\
\text { (metal side) } \\
d_{y z}\end{array}$ & 0.86 & 0.10 & 0.10 & 0.04 \\
\hline $\begin{array}{c}3^{\text {rd }} \alpha \text {-PISO } \\
\text { (metal side) } \\
\text { s }\end{array}$ & 0.02 & 0.01 & 0.00 & 0.95 \\
\hline $\begin{array}{c}4^{\text {th }} \alpha \text {-PISO } \\
\text { (metal side) } \\
d_{x z}\end{array}$ & 0.07 & 0.07 & 0.99 & 0.01 \\
\hline
\end{tabular}

Table S5. Overlap matrix between the metal fragment $\alpha$-PISOs and SNOs shown in Figure 4.

\begin{tabular}{ccccc}
\hline $\begin{array}{c}\text { Orbital } \\
\text { overlap }\end{array}$ & $\begin{array}{c}1^{\text {st }} \alpha \text {-PISO } \\
(\text { metal side) } \\
\mathrm{d}_{\mathrm{xy}}\end{array}$ & $\begin{array}{c}2^{\text {nd }} \alpha \text {-PISO } \\
(\text { metal side) } \\
\mathrm{d}_{\mathrm{yz}}\end{array}$ & $\begin{array}{c}3^{\text {rd }} \alpha \text {-PISO } \\
\text { (metal side) }\end{array}$ & $\begin{array}{c}4^{\text {th }} \alpha \text {-PISO } \\
\text { (metal side) } \\
\mathrm{d}_{\mathrm{xz}}\end{array}$ \\
\hline $\begin{array}{c}1^{\text {st }} \alpha-\text { SNO } \\
\mathrm{d}_{z 2}\end{array}$ & 0.02 & 0.02 & 0.01 & 0.02 \\
$1^{\text {st } \beta-S N O}$ & 0.05 & 0.18 & 0.03 & 0.01 \\
$\pi^{*}$ & & & & \\
\hline
\end{tabular}


Table S6. Overlap matrix between the metal fragment $\beta$-PISOs and SNOs shown in Figure 4.

\begin{tabular}{|c|c|c|c|c|}
\hline $\begin{array}{l}\text { Orbital } \\
\text { overlap }\end{array}$ & $\begin{array}{c}1^{\mathrm{st}} \beta \text {-PISO } \\
\text { (metal side) } \\
\mathrm{d}_{\mathrm{yz}}\end{array}$ & $\begin{array}{c}2^{\text {nd }} \beta \text {-PISO } \\
\text { (metal side) } \\
d_{x y}\end{array}$ & $\begin{array}{c}3^{\text {rd }} \beta \text {-PISO } \\
\text { (metal side) } \\
d_{x z}\end{array}$ & $\begin{array}{c}4^{\text {th }} \beta \text {-PISO } \\
\text { (metal side) } \\
\mathrm{s}\end{array}$ \\
\hline $\begin{array}{c}1^{\text {st }} \alpha-\mathrm{SNO} \\
\mathrm{d}_{\mathrm{z} 2}\end{array}$ & 0.10 & 0.03 & 0.01 & 0.30 \\
\hline $\begin{array}{c}1^{\text {st }} \beta-\mathrm{SNO} \\
\pi^{*}\end{array}$ & 0.28 & 0.04 & 0.03 & 0.03 \\
\hline
\end{tabular}

Table S7. Total PBI of resting state and key transition states with the corresponding free energy differences (given in $\mathrm{kcal} / \mathrm{mol}$ ).

\begin{tabular}{ccccc}
\hline & IMO & TS $_{\mathrm{OC}}$ & TS $_{\mathrm{BHT}}$ & TS $_{\mathrm{RE}}$ \\
Total PBI(T) & 1.789 & 1.646 & 1.825 & 1.626 \\
Total PBI(S) & 2.147 & 2.670 & 2.703 & 2.059 \\
$\mathrm{G}(\mathrm{T})-\mathrm{G}(\mathrm{S})$ & 2.8 & 8.3 & 7.5 & -9.0 \\
\hline
\end{tabular}


Table S8. Calculated relative energies (in $\mathrm{kcal} / \mathrm{mol}$ ) based on full model (TPSSh) and truncated model (TPSSh and CASPT2).

\begin{tabular}{ccccccc}
\hline Species & $\Delta \mathrm{E}^{\text {full }}($ TPSSh $)$ & $\Delta \mathrm{G}^{\text {full }}($ TPSSh) & $\Delta \mathrm{E}^{\text {trunc }}($ TPSSh) & $\Delta \mathrm{G}^{\text {trunc }}($ TPSSh) & $\Delta \mathrm{E}^{\text {trunc }}($ CASPT2) & $\Delta \mathrm{G}^{\text {trunc }}($ CASPT2) \\
\hline${ }^{1} \mathrm{TS}_{\text {BHT }}$ & 0.0 & 0.0 & 0.0 & 0.0 & 0.0 & 0.0 \\
${ }^{3}{ }^{3} \mathrm{TS}_{\mathrm{RE}}$ & 8.0 & 5.7 & 6.7 & 4.4 & 4.6 & 2.3 \\
${ }^{3} \mathbf{T S}_{\text {BHT }}$ & 12.1 & 7.5 & 12.2 & 7.7 & 7.5 & 3.0 \\
\hline
\end{tabular}

Note for Table S8: In order to confirm the spin sate preference predicted by (U)TPSSh, we performed $a b$ initio multi-reference calculations at the level of CASPT2 $(6,6) / \mathrm{def} 2 \mathrm{TZVP}-6-311++\mathrm{G}(\mathrm{d}, \mathrm{p})$. The truncation models presented in Scheme S1 were used to reduce the computational cost in the CASPT2 calculations. Table $\mathbf{S 2}$ shows that the relative energies calculated using CASPT2 based on truncated models are similar with those using TPSSh based on truncated models, being consistent with the spin state preference presented in the main text using TPSSh based on full models.

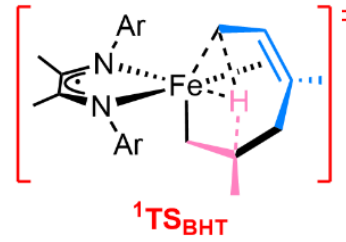

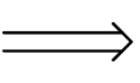

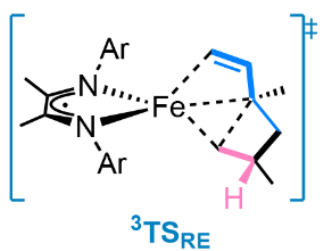

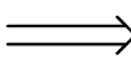

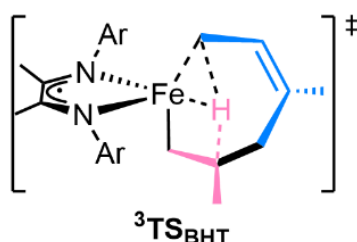

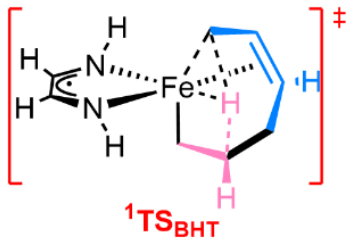

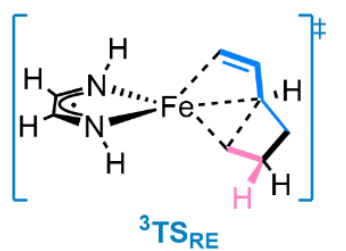

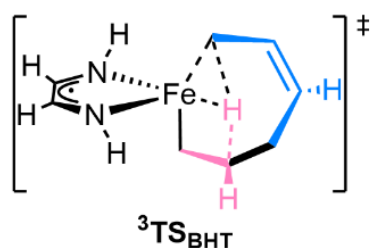

Scheme S1. Truncation scheme for CASPT2 calculations; Both methyl groups and phenyl groups of the ligand and substrates were changed to $\mathrm{H}$ atoms; All three species were optimized with all the fragments fixed except for the newly added $\mathrm{H}$ atoms; The optimization were carried out at the level of TPSSh/def2TZVP-6-311++G(d,p). 